\title{
ANALISIS PRODUKTIVITAS DAN LUAS TANAMAN JERUK SIAM SAMBAS TAHUN 2015-2020
}

\section{ANAL YSIS OF PRODUCTIVITY AND AREA OF SIAM ORANGE PLANTS SAMBAS 2015-2020}

\author{
Kiki Kristiandi*¹, Rini Fertiasari ${ }^{1}$, Nurul Fatimah Yunita ${ }^{2}$, \\ Theresia Widji Astuti ${ }^{3}$, Dian Sari ${ }^{4}$ \\ ${ }^{1}$ Program Studi Agroindustri Pangan Jurusan Agribisnis Politeknik Negeri Sambas \\ ${ }^{2}$ Program Studi Agribisnis Perikanan dan Kelautan Jurusan Agribisnis Politeknik Negeri Sambas \\ ${ }^{3}$ Program Studi Manajemen informatika Jurusan Manajemen Informatika Politeknik Negeri Sambas \\ ${ }^{4}$ Program Studi Agrobisnis Jurusan Agribisnis Politeknik Negeri Sambas \\ *E-mail: kikikristiandi2020@gmai.com \\ (Diterima 10-07-2021; Disetujui 22-07-2021)
}

\begin{abstract}
ABSTRAK
Jeruk siam merupakan komoditas Kabupaten Sambas dan menjadi salah satu jenis pertanian yang dikembangkan oleh pemerintah Kabupaten Sambas, selain itu pula Kabupaten Sambas menjadi wilayah percontohan dalam bidang pertanian di Kalimantan Barat. Tujuan dalam penelitian ini adalah menganalisis tingkat luas tanaman dan produktifitas jeruk siam pada tahun 2015-2020. Adapun pendekatan penelitian ini adalah cross sectional study. Data ini merupakan data sekunder dengan deret waktu (time series) yang diperoleh dari Dinas Pertanian dan Ketahanan Pangan Kabupaten Sambas. Selain itu, penelitian ini merupakan kuantitatif deskriptif. Hasil penelitian menunjukan bahwa Kecamatan Tebas menjadi salah satu wilayah yang memiliki tingkat perluasan tanaman diantara Kabupaten lainnya, sedangkan untuk produktifitas $(\mathrm{kg} /$ pohon) paling banyak terdapat di Kecamatan Sebawi, Sambas, Jawai, Jawai Selatan, Tebas, Semparuk, Salatiga, Teluk Keramat, Tekarang, Selakau timur, Pemangkat, dan Selakau. Rata-rata hasil produktifitas jeruk siam berkisar $33 \mathrm{~kg} /$ pohon. Peningkatan jumlah luas tanaman dan produkktifitas pada jeruk siam di Kabupaten Sambas menjadi salah satu peluang usaha dalam bidang pertanian dan hasil pertanian tersebut dapat dikembangkan menjadi olahan lain seperti pangan dan non pangan.
\end{abstract}

Kata Kunci: Luas Tanaman, Produktifitas, Jeruk Siam

\section{ABSTRACT}

Siam orange is a commodity of Sambas district and is one of the types of agriculture developed by the Sambas district government, besides that, Sambas district is a pilot area in the agricultural sector in West Kalimantan. The purpose of this study was to analyze the level of plant area and productivity of Siam oranges in 2015-2020. The research approach is a cross sectional study. This data is secondary data with a time series (time series) obtained from the Department of Agriculture and Food Security of Sambas Regency. In addition, this research is quantitative descriptive. The results showed that Tebas District is one of the areas that has a plant expansion rate among other districts, while productivity (kg/tree) is mostly found in Sebawi, Sambas, Jawai, South Jawai, Tebas, Semparuk, Salatiga, Teluk Keramat Districts. Tekarang, Selakau timur, Pemangkat and Selakau. Average productivity results. Siam orange ranges from $33 \mathrm{~kg} /$ tree. Increasing the number of plants and products in chayote in Sambas Regency is one of the business opportunities in the agricultural sector and agricultural products can be developed into other preparations such as food and non food.

Keywords: Plant Area, Productivity, Siam Orange 


\section{PENDAHULUAN}

Kabupaten/Kota

Sambas

merupakan salah satu wilayah yang terletak di Kalimantan Barat. Komoditas hasil pertanian yang terdapat di Sambas berupa alpukat, belimbing, langsat, durian, jambu biji, jambu air, jeruk siam, jeruk besar, mangga, manggis, nangka/campedak, nanas, pepaya, pisang, rambutan, salak, sawo, markisa, sirsak, sukun, petai dan jengkol. Berdasarkan tingkat populasi hasil pertanian terbanyak adalah di Sambas adalah Jeruk Siam (BPS, 2020). Jeruk siam merupakan tumbuhan yang banyak ditemukan di Sambas terbanyak pada saat musim panen. Selain itu pula jenis jeruk ini banyak dibudidayakan di Indonesia (Kristiandi \& Sambas, 2020)

Jeruk siam merupakan komoditas hortikultura yang dapat tumbuh dan berproduksi di dataran rendah dan tinggi, selain itu tumbuhan jenis ini pun dapat tumbuh pada lahan pesawahan maupun tegalan (Aluhariandu et al., 2016). Jeruk siam menjadi tumbuhan yang dapat bernilai ekonomi tinggi. Hal ini dikarenakan tumbuhan jeruk siam merupakan buah yang disukai semua kalangan. Selain itu pula jeruk siam menjadi salah satu buah pengahasil vitamin $\mathrm{C}$.
Selama 5 tahun produksi jeruk (jeruk siam, jeruk keprok, jeruk nipis, jeruk purut, jeruk bali, jeruk nambangan dan jenis jeruk lainnya) di Indonesia mengalami peningkatan sebanyak 0,38 Juta ton dari tahun 2014-2018. Sekitar 70-80\% jeruk yang dikembangkan di Indonesia adalah jeruk siam dan $20-30 \%$ adalah jeruk keprok (Qomariah, 2013). Hal tersebut menunjukan bahwa tingkat pertumbuhan dan produksi jeruk menjadi salah satu jenis buah yang digemari masyarakat.

Permentan 830/Kpst/RC.040/12/2016 menjelaskan bahwa melalui pengembangan kawasan hortikultura jeruk ditetapkan sentra utama produksi jeruk lokal di Jawa Timur, Sulawesi Selatan, Kalimantan Selatan, Kalimantan Timur, Kalimantan Barat, dan beberapa lokasi lainnya. Pengembangan tersebut dilakukan guna meningkatkan kesejahteraan masyarakat dan diharapkan membangun perekonomian daerah. Hal ini pun didukung keputusan Bupati Sambas tahun 2001 tentang penetapan jeruk sebagai komoditas unggalan daerah Kabupaten Sambas. Dukungan ini pun dilakukan dalam rangka mengembalikan kejayaan jeruk siam di wilayah kota tersebut. 
Jeruk siam memiliki ciri khas dengan kulit buahnya tipis (sekitar 2 $\mathrm{mm}$ ), permukaannya halus, licin dan kulitnya menempel lekat pada daging buahnya, selain itu tangkai pendek dengan panjang $3 \mathrm{~cm}$ dan diameter 2,6 $\mathrm{mm}$, biji buah berbentuk avoid, warna putih kekuning-kuningandan jumlah biji per buahnya sekitar 20 biji. Produksi dari satu buah pohon jeruk siam dapat mengahasilkan 7-8 $\mathrm{kg}$ buah. Pemanen pada buah tersebut pada bulan MeiAgustus. Klasifikasi jeruk siam menurut USDA (2017) termasuk kedalam jenis citrus nobilis Lour. Var Microcarpa. Penelitian ini bertujuan untuk menganalisis tingkat pertumbuhan jeruk siam Sambas tahun 2015-2020. Sehingga dengan adanya penelitian ini diharapkan dapat menjadi pengembangan pengetahuan di bidang pertanian khusus jeruk siam terutama dalam pemanfaatan sumber daya lokal dan menjadi informasi kepada masyarakat.

\section{METODE PENELITIAN}

Penelitian ini berlangsung dari bulan Januari-Februari 2021 dengan menggunakan pendekatan cross sectional study. Data ini merupakan data sekunder dengan deret waktu (time series) 20152020 yang didapatkan dari Dinas
Pertanian dan Ketahanan Pangan Sambas. Penelitian ini menggunakan data pertumbuhan buah jeruk siam di Kabupaten/Kota Sambas Kalimantan Barat. Selain itu penelitian ini merupakan kuantitatif deskriptif dengan fokus pada luas tanaman produksi jeruk siam dan produktivitas jeruk siam

Data yang digunakan dalam penelitian ini seluruhnya merupakan data sekunder yang diperoleh dari Dinas Pertanian dan Ketahanan Pangan Sambas, Kalimantan Barat. Adapun bentuk data yang tersaji adalah electronic file berupa entry data yang dilakukan oleh tim Dinas Pertanian dan Ketahanan Pangan. Sampel yang diperoleh dalam penelitian ini sebanyak 19 kecamatan. Sampel dipilih berdasarkan data yang tersaji dengan kriteria bahwa setiap kecamatan memiliki tingkat produksi hasil pertanian jeruk siam, untuk data yang tidak muncul meskipun masuk dalam 19 kecamatan tersebut tidak dijadikan sebagai sampel. Teknik yang digunakan dalam pengambilan sampel yaitu secara purposive sampling.

Data yang telah diperoleh diolah dnegan menggunakan Microsoft Office Excel 2013. Proses dalam pengolahan data tersebut meliputi editing dan cleaning data. Proses cleaning bertujuan 
untuk memastikan bahwa data sesuai dengan peubah yang ditentukan. Selanjutnya analisis data dalam penelitian ini hanya menganalisis tingkat pertumbuhan buah jeruk siam dari tahun 2015-2020.

\section{HASIL DAN PEMBAHASAN}

\section{Luas Tanaman}

Berdasarkan Gambar 1 menunjukan bahwa luas tanaman jeruk siam pada 19 kecamatan dengan rentang waktu 2015-
2020 terdapat di wilayah Tebas. Luas tanaman di Wilayah Tebas termasuk yang mengalami peningkatan secara berlanjut. Hal tersebut disebabkan karena Tebas menjadi salah satu wilayah di Kabupaten Sambas yang mengalami peningkatan produksi secara konsisten, selain itu pemerintah Kabupaten Sambas mendukung terhadap kemajuan produksi jeruk siam agar dapat membantu perekonomian dan juga menjadi ciri khas dari Kabupaten Sambas.

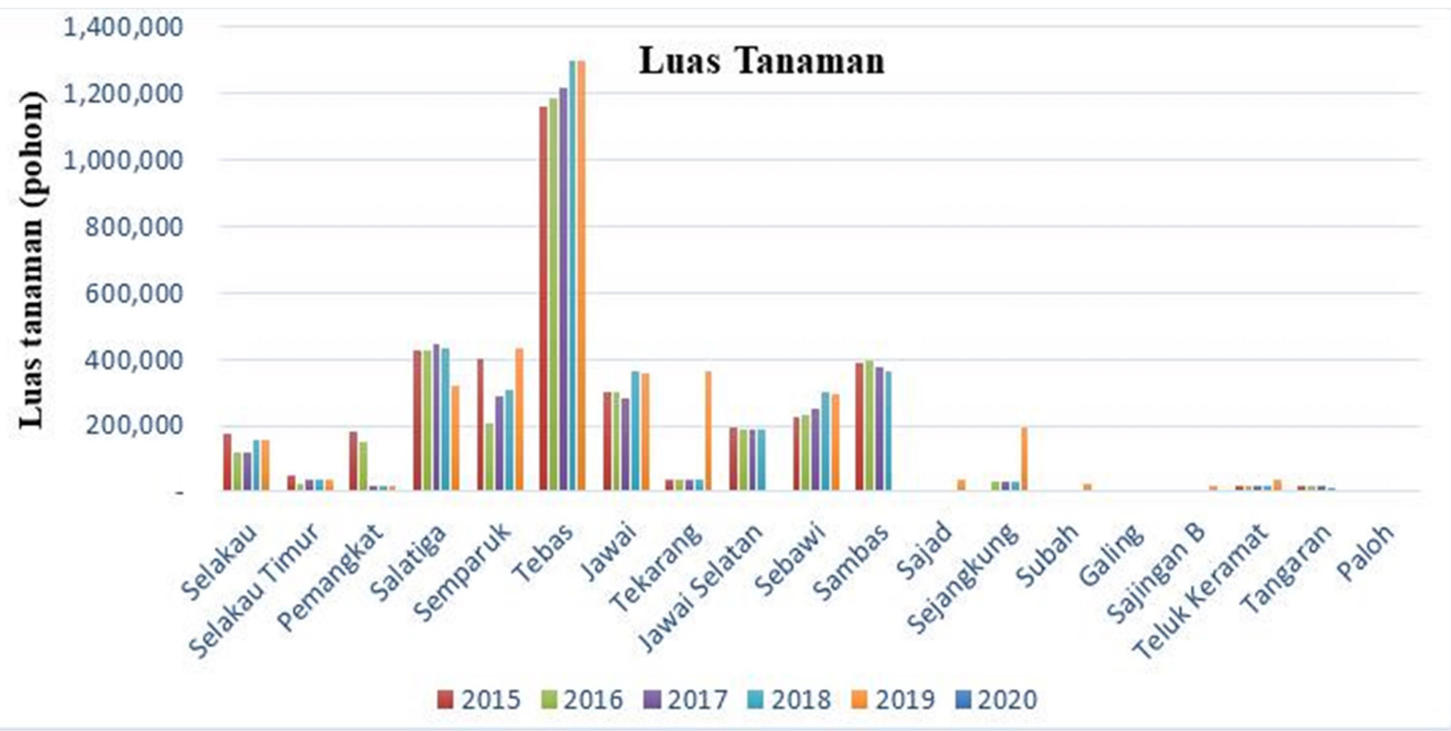

Gambar 1. Luas tanaman jeruk siam

Sedangkan untuk 18 kecamatan yang berada pada Kabupaten Sambas memiliki karakteristik pertanian yang tidak hanya terfokus pada komoditi jeruk tetapi jenis pertanian lainnya, seperti Jawai dengan hasil pertanian kelapa, sejangkung dengan karet, Teluk Keramat salak, Subah kebun sawit, Paloh dan
Galing dengan lada dan beberapa kecamatan lain yang terfokus pada pisang dan jenis pertanian lainnya. (Kartini et al., 2018; Romdhon et al., 2018), Peningkatan luas tanaman di wilayah Tebas termasuk dalam kategori konsisten untuk pertumbuhan jeruk siam dibandingkan dengan kecamatan lainnya. 
Hal ini karena masing-masing kecamatan memiliki ciri khas dalam pertaniannya.

Tebas menjadi wilayah dengan penghasil jeruk terbanyak karena wilayah tersebut menjadi salah satu ikon dalam memproduksi jeruk siam di Kabupaten/Kota Sambas, selain itu pula Tebas menjadi wilayah yang konsisten dalam memproduksi jeruk siam (Amri et al., 2020).

Syarat pengembangan pertanian menurtu Monsher (2014) adalah hasil dari pertanian dapat dijual pada pasar, penerapan teknologi, tersedianya bahan dan alat produksi secara lokal, perangsang produksi bagi petani dan tersedianya pengakutan yang lancar dan berkelanjutan.

Perluasan tanaman dalam agribisnis diartikan sebagai kegiatan yang ditunjukan untuk mendapatkan keuntungan, tenaga kerja, pemanfaatan lahan yang tidak produktif, pemasaran dan kepentingan dalam peningkatan produktifitas lainnya (Ekaputri, 2008; Ha, 2019; Soepono, 2001).

Luas tanaman pada suatu wilayah pertanian dapat dirumuskan sebagai sebuah rangkaian untuk mewujudkan penggunaan sumberdaya, menyeimbangkan pembangunan nasional dan kesatuan wilayah nasional serta proses penataan ruang guna mencapai tujuan pembangunan berkelanjutan sesuai dengan RPJMD Kabupaten Sambas tahun 2016-2021.

\section{Tingkat Produktivitas Jeruk Siam}

Jeruk siam sebagai salah satu sentra utama dan termasuk jeruk lokal yang berada di Indoneisa dimana berdasarkan Gambar 2 menunjukan bahwa produktifitas jeruk siam (kg/pohon) secara dominan terdapat di beberapa kecamatan yaitu Sebawi, Sambas, Jawai, Jawai Selatan, Tebas, Semparuk, Salatiga, Teluk Keramat, Tekarang, Selakau timur, Pemangkat, Selakau sedangkan untuk kecamatan cenderung peningkatan yang tidak terlalu optimal. Penyebab penyebaran produktifitas jeruk tidak merata di beberapa kecamatan yang berada di wilayah Kabupaten Sambas karena kecamatan tertentu memiliki fokus hasil pertanian yang berbeda, seperti kelapa, petai, pisang, padi dan jenis hasil pertanian lainnya.

Potensi yang dimiliki Kabupaten Sambas sebagai salah satu wilayah sentra jeruk siam adalah dapat berdaya saing dan berpotensi meningkatkan perekonomian masyarakat setempat. Daya saing tersebut dapat menggambarkan keunggulan suatu wilayah dan memberikan nilai positif 
terhadap pengembangan Kabupaten yang mencirikan wilayah tersebut. Upaya peningkatan produktifitas di Kabupaten Sambas telah dilakukan pada tahun 2001 tentang penetapan jeruk sebagai komoditas unggalan daerah Kabupaten Sambas dan didukung pula oleh Menteri Pertanian Republik Indonesia tentang pengembangan Kawasan Pertanian Nasional yang tertuang dalam Permentan 830/Kpst/RC.040./12/2016.
Rata-rata peningkatan tersebut terjadi pada tahun 2020 (Gambar 2). Berdasarkan data tersebut menunjukan adanya upaya pemerintah Kabupaten Sambas terhadap petumbuhan ekonomi daerah. Pertumbuhan ekonomi pada suatu wilayah pada dasarnya dipengaruhi oleh keunggulan komperatif, selain itu pula dari peningkatan produktifitas dapat memberikan perbaikan dan peningkatan pasar.

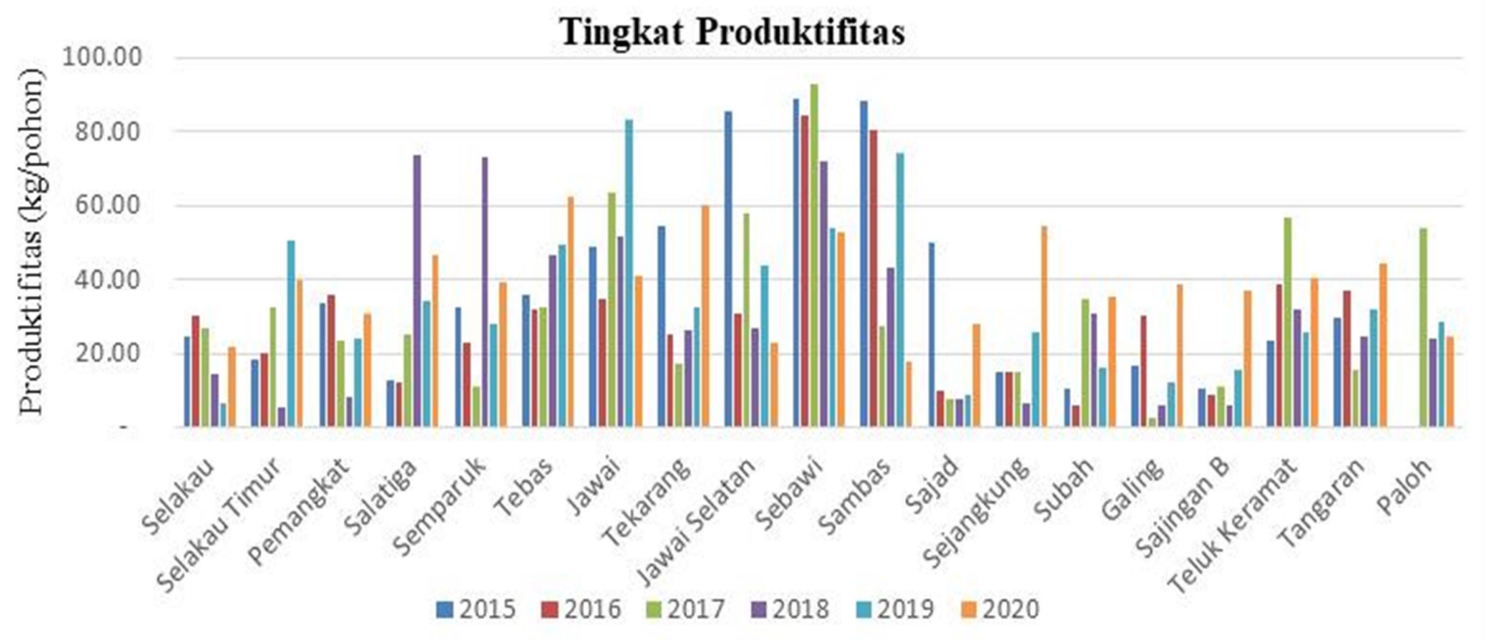

Gambar 2. Produktifitas jeruk siam

Peranan pada sektor pertanian dalam pengembangan termasuk sangat penting untuk setiap wilayah, karena dengan tinggi rendahnya tingkat produksi hasil pertanian dapat menentukan faktor tinggi rendahnya Produk Domestik Regional Bruto (PDRB) (Ardiansyah, 2019; Primilestari \& Purnama, 2019; Wulandari et al., 2014). Tantangan lain yang diterima pada masa yang akan datang adalah mengantisipasi permintaan pasar, menjamin kualitas bahan baku, menciptakan nilai tambah, penyesuaian harga agar tidak terjadi penurunan harga yang dapat merugikan petani jeruk (Azmi, 2016; Gunawan, 2017; Hukom et al., 2019). 
Rata-rata Hasil Produktifitas Tahun 20152020

Berdasarkan tabel 1 menunjukan bahwa rata-rata produktivitas jeruk siam Sambas dapat mencapai $33 \mathrm{~kg} /$ pohon, jumlah produktivitas paling banyak dihasilkan pada kecamatan Sebawai 74 $\mathrm{kg} /$ pohon, Sambas $55 \mathrm{~kg} /$ pohon dan 54 $\mathrm{kg} /$ pohon di kecamatan Tebas. Sedangkan untuk tahun 2020 produktifiktas jeruk siam berada pada rata-rata $38,93 \mathrm{~kg} /$ pohon, hal ini mengalami peningkatan dari tahun sebelumnya 34,06 kg/tahun dan sekaligus menjadi jumlah paling terbanyak dalam kurun waktu 2015-2020. Peningkatan jumlah produktifitas pada tahun 2020 merupakan bagian dari rencana Kabupaten Sambas dalam peningkatan komoditas tanaman hortikultura. Salah satu yang menyebabkan terjadinya peningkatan produktifitas jeruk siam di Kabupaten Sambas.

Tabel 1 Rata-rata produktifitas jeruk siam tahun 2015-2020

\begin{tabular}{|c|c|c|c|c|c|c|c|c|c|}
\hline \multirow[t]{2}{*}{ No } & \multirow[t]{2}{*}{ Wilayah } & \multicolumn{6}{|c|}{ Produktivitas (kg/pohon) } & \multirow[t]{2}{*}{$\widetilde{\boldsymbol{X}}$} & \multirow[t]{2}{*}{ SD } \\
\hline & & 2015 & 2016 & 2017 & 2018 & 2019 & 2020 & & \\
\hline 1 & Selakau & 24,50 & 30,52 & 26,79 & 14,40 & 6,69 & 22,00 & 21 & 9 \\
\hline 2 & Selakau Timur & 18,69 & 20,00 & 32,67 & 5,58 & 50,72 & 39,70 & 28 & 16 \\
\hline 3 & Pemangkat & 33,78 & 36,09 & 23,50 & 8,25 & 23,83 & 31,08 & 26 & 10 \\
\hline 4 & Salatiga & 12,64 & 12,16 & 25,15 & 73,69 & 34,26 & 46,58 & 34 & 23 \\
\hline 5 & Semparuk & 32,42 & 23,03 & 11,25 & 73,00 & 27,97 & 39,37 & 35 & 21 \\
\hline 6 & Tebas & 35,92 & 32,14 & 32,50 & 46,69 & 49,45 & 62,44 & 43 & 12 \\
\hline 7 & Jawai & 48,85 & 35,04 & 63,42 & 51,63 & 83,46 & 40,98 & 54 & 17 \\
\hline 8 & Tekarang & 54,76 & 25,18 & 17,54 & 26,56 & 32,66 & 60,13 & 36 & 17 \\
\hline 9 & Jawai Selatan & 85,81 & 31,02 & 57,97 & 26,73 & 44,07 & 23,06 & 45 & 24 \\
\hline 10 & Sebawi & 89,25 & 84,41 & 93,11 & 72,24 & 54,28 & 53,00 & 74 & 18 \\
\hline 11 & Sambas & 88,34 & 80,71 & 27,34 & 43,54 & 74,28 & 18,06 & 55 & 30 \\
\hline 12 & Sajad & 49,86 & 9,90 & 7,46 & 7,90 & 8,71 & 28,00 & 19 & 17 \\
\hline 13 & Sejangkung & 14,80 & 15,16 & 15,25 & 6,56 & 26,00 & 54,74 & 22 & 17 \\
\hline 14 & Subah & 10,71 & 6,15 & 34,67 & 31,00 & 15,97 & 35,31 & 22 & 13 \\
\hline 15 & Galing & 16,52 & 30,52 & 2,89 & 5,78 & 12,44 & 39,00 & 18 & 14 \\
\hline 16 & Sajingan B & 10,57 & 9,00 & 11,00 & 5,87 & 15,78 & 36,92 & 15 & 11 \\
\hline 17 & Teluk Keramat & 23,50 & 38,57 & 57,00 & 32,14 & 25,62 & 40,20 & 36 & 12 \\
\hline 18 & Tangaran & 29,68 & 37,00 & 15,43 & 24,67 & 32,29 & 44,44 & 31 & 10 \\
\hline \multirow[t]{2}{*}{19} & Paloh & - & - & 54,25 & 24,04 & 28,57 & 24,71 & 22 & 20 \\
\hline & Total $\widetilde{X}$ & 35,82 & 29,30 & 32,06 & 30,54 & 34,06 & 38,93 & 33 & \\
\hline
\end{tabular}

Berdasarkan Perda No 2 tahun 2010, perkembangan jeruk siam Sambas akan tetap dipertahankan menjadi komoditas utama Kabupaten Sambas dan apabila jeruk siam mengalami kerusakan yang mengakibatkan jeruk siam tidak dapat berproduksi kembali maka pemerintahan Kabupaten Sambas siap melakukan proses penanaman kembali. Hal ini pun sejalan dengan target 
Kementan (2020), bahwa produksi jeruk siam di Indonesia harus mengalami peningkatan agar tidak terjadi impor dari luar dan terpenuhinya kebutuhan asupan pangan buah untuk masyarakat Indonesia.

\section{KESIMPULAN}

Peningkatan produktifitas pada tanaman hortikultura jeruk siam di Kabupaten Sambas memberikan gambaran bahwa keseriusan pemerintahan Kabupaten Sambas dalam mengembangkan wilayahnya menjadi penghasil komoditas jeruk siam dan sejalan dengan target yang direncanakan oleh kementrian pertanian, selain itu bahwa jumlah hasil produksi dapat menjadi peluang terhadap petani dan stakeholders lainnya dalam mengembangkan hasil jeruk siam ke dalam bentuk olahan lain, sehingga hasil produksi jeruk siam yang diperoleh tidak saja bentuk buah segar namun dapat menjadi bentuk olahan pangan lain yang memiliki mutu gizi baik. Pengolahan jeruk siam dapat juga membantu petani dalam menjaga kestabilan harga dan tidak berdampak pada meruginya petani jeruk siam.

\section{DAFTAR PUSTAKA}

Aluhariandu, V. E., Tariningsih, D., \& Lestari, P. F. K. (2016). Analisis usahatani jeruk siam dan faktor faktor yang memepengaruhi penerimaan petani (studi kasus di desa bayung gede kecamatan kintamani Kabupaten bangli). Agrimeta, 6(12), 77-86.

Amri, K., Siswanto, J., \& Roshayanti, F. (2020). potensi pengelolaan jeruk siam ( citrus reticulatae) sebagai sumber belajar berbasis sustainability ( studi kasus kecamatan tebas ). 1, 77-85.

Ardiansyah, M. (2019). Perbandingan Data Produktivitas Padi Antara Hasil Wawancara Pascapanen dengan Data Survei Ubinan di Kalimantan Tengah A Comparison of Rice Productivity Data Between Post-Harvest Interview and Ubinan Survey in Central Kalimantan.

Azmi, N. (2016). Faktor-Faktor Yang Mempengaruhi Produksi Jeruk Besar (Citrus Grandis L. Osbeck) Di Kabupaten Aceh Besar. Jurnal Ilmiah Mahasiswa, 1(1), 158-168.

BPS [Badan Pusat Statistik]. (2021). Jumlah Tanaman Menghasilkan dan Produksi Tanaman BuahBuahan dan Sayuran Tahunan di Kabupaten Sambas Tahun 20162018. (diakses 12 Februari 2020)

Ekaputri, N. (2008). Harvested Area Influence to Production of Food and Estate Crops in East Kalimantan. Pengaruh Luas Panen Terhadap Produksi Tanaman Pangan Dan Perkebunan Di Kalimantan Timur, 5(2), 36-43.

Gunawan, C. I. (2017). Pengaruh Luas Lahan, Produktivitas Konsumsi Beras, dan Nilai Tukar Petani Terhadap Ketahanan Pangan di Kabupaten Brebes. Universitas Negeri Semarang, 1-97.

Ha, T. (2019). Luas Panen Jeruk Siam / Keprok Menurut Provinsi, Tahun 2015-2019. 2019, 2019.

Hukom, J., Kakisina, L. O., Sari, R. M., 
Agribisnis, P., Pertanian, F., Pattimura, U., Putuhena, J. I. M., \& Poka, K. (2019). Passo Kecamatan Baguala Kota Ambon Productivity Analysis of Leaf Vegetables in Passo Village Baguala District Ambon City. AGRILAN: Jurnal Agribisnis Kepulauan, 7(3), 227240.

Kartini, K., Krisnawan, A. H., \& Jayani, N. I. E. (2018). Peningkatan Produktivitas Petani Dalam Pengolahan Jeruk Nipis Menjadi Produk Minuman Kesehatan Dan Sabun. Abdimas: Jurnal Pengabdian Kepada Masyarakat, 11(1). https://doi.org/10.36412/abdimas.v $11 \mathrm{i} 1.547$

Kristiandi, K., \& Sambas, P. N. (2020). Pemanfaatan kulit jeruk siam sebagai pestisida alami utilization of siam orange skin as a natural pesticide. 6(2), 46-52.

Kementan [Kementrian Pertanian]. (2020). Sinta Ponsoe Varietas Baru Hasil Persilangan Siam Pontianak dengan Keprok soe. http://balitjestro.litbang.pertan ian.go.id/tag/jeruk-siam/. (diakses 13 Februari 2021)

Primilestari, S., \& Purnama, H. (2019). Teknologi budidaya jeruk di lahan gambut untuk meningkatkan produktivitas dan pendapatan petani di Kabupaten Tanjung Jabung Barat. Prosiding Seminar Nasional Lahan Suboptimal, September, 978-979.
Qomariah R, Hasbianto A, Lesmayati S dan Hasan H. 2013. Kajian prapanen jeruk siam (Citrus suhuiensis Tan) untuk ekspor. Seminar Nasional Inovasi Teknologi Pertanian. Balai Pengkajian Teknologi Pertanian Kalimantan Selatan (ID): hlm 417430.

Romdhon, M. M., Andani, A., \& Nasari, W. F. (2018). comparative advantage of siamese orange (cITRUS nOBILIS) farming in district of 50 kota, west sumatera. agritropica : Journal of Agricultural Sciences, 1(2), 62-67. https://doi.org/10.31186/j.agritropic a.1.2.62-67

Soepono, $\quad P$. (2001). Kajian Pengembangan Komoditas Unggulan Buah-Buahan. Jurnal $\bar{E}$ konomi Dan Bisnis Indonesia, 16(1), 41-53.

Wulandari, M., Hartadi, R., \& Agustina, T. (2014). Analysis Production and Revenue also the Commodity Development Strategies of Citrus Nobilis in Bangorejo Banyuwangi. Berkala Ilmiah Pertanian, November, 1-12. 